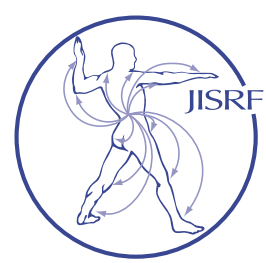

\title{
What is Considered a Conflict of Interest or What to Disclose in Lectures and Publications?
}

McTighe $T^{1}$

$\mathrm{R}$ ecently our Journal was criticized for allowing a co-author to submit and publish a technical paper when said surgeon is involved in a litigation matter. "I am very surprised indeed that you do not consider being a defendant in legal action concerning the very practice being defended in an article amounts to a conflict of interest."

This made me think it might be an appropriate time to revisit this issue. I think it is important to understand some of the history regarding disclosure and conflict of interest.

What should a conflict of interest policy include when it comes to Continuing Medical Education (CME)? One might think this is an easy question but I have been involved with this question since the 1990s and find that it is one of the more difficult areas of debate. [1]

A policy on conflict of interest (COI) should require those with a conflict (or who think they may have a conflict) to disclose the conflict or potential conflict.

CME in the United States clearly dates back to the formation of the American Medical Association (AMA) in 1873 with publication of its first publication in 1883 Journal of the American Medical Association (JAMA).

This issue of COI has been much discussed and debated over the years and the topic of FDA investigation back in 1991and 1992 resulting in a 1995 publication The Statutory Basis for FDA Regulation of Scientific and Educational Information. []]

The Accreditation Council for Continuing Medical Education (ACCME) intervened in 1992 and was successful in pointing out to the FDA that a governing body was al- ready in place concerning $\mathrm{CME}$ activities. However, the FDA did instruct the ACCME that if they changed their guidelines concerning commercial support of CME activities to standards they would basically back off from official involvement. As a result ACCME in 1992 adopted new standards for all ACCME accredited sponsors.

These 1992 standards have been the foundation for many organizations in establishing their own guidelines and standards for educational activities into publications. The ACCME has updated their Standards in 2004, 2005 and more recently in 2014. []]

\section{ACCME Standards}

1. General Responsibilities of Accredited Sponsors The accredited sponsors are responsible for the content, quality, and scientific integrity of all CME activities certified for credit. Identification of continuing medical education needs, determination of educational objectives, and selection of content, faculty, educational methods and materials is the responsibility of the accredited sponsor. Similarly, evaluation must be designed and performed by the accredited sponsor.

2. Enduring Materials - The accredited sponsors are responsible for the quality, content, and use of enduring materials for purposes of CME credit.

3. Identifying Products, Reporting on Research and

Keywords: conflict of interest; disclosures; lectures; publications 
Discussing Un-Labeled Use of Products - Presentations must give a balanced view of options. Faculty use of generic names will contribute to the impartiality. If trade names are used, those of several companies should be used rather than only that of a single supporting company. Reporting scientific research offered by a commercial entity to provide a presentation reporting the results of scientific research shall be accompanied by a detailed outline in the presentation, which shall be used by the accredited sponsor to confirm the scientific objectivity of the presentation. Concerning unlabeled uses of products or an investigational use not yet approved for any purpose is discussed during the educational activity, the accredited sponsor shall require the speaker to disclose that the product is not labeled for the use under discussion or that the product is still investigational.

4. Exhibits and Other Commercial Activities - When commercial exhibits are part of the overall program, arrangements for these should not influence planning or interfere with presentation of CME activities. Exhibit placement should not be a condition of support for CME activity. No commercial, promotional material shall be displayed or distributed in the same room immediately before, during, or immediately after an educational activity certified for credit. Representatives of commercial supporters may attend an educational activity but not engage in sales activities while in the room where the activity takes place.

5. Management of Funds from Commercial Sources The ultimate decision regarding funding arrangements for CME activities must be the responsibility of the accredited sponsor. Funds from a commercial source should be in the form of an educational grant made payable to the accredited sponsor for the support of programming. The terms, conditions, and purposes of such grants must be documented by a single agreement between the commercial supporter and the accredited sponsor. No other funds from a chimerical source shall be paid to the director of the selectivity. Payment of reasonable honoraria and reimbursement of out of pocket expenses for faculty is customary and proper. Commercial support must be acknowledged in printed announcements and brochures. However, reference must not be made to specific products.

6. Commercially Supported Social Event - Should not compete with nor take precedence over the educational events.

7. Policy On Disclosure of Faculty and Sponsor Relationships - An accredited sponsor shall have a policy disclosure of the existence of any significant financial interest or other relationship a faculty member or a sponsor has with the manufacturer of any commercial products discussed in an educational presentation.
8. Financial Support for Participants in Educational Activities - In connection with an educational activity offered by an accredited sponsor, the sponsor may not use funds originating from a commercial source to pay travel, lodging, registration fees, honoraria, or personal expenses for non-faculty attendees. Scholarships or other special funding to permit medical Students, residents, or fellows to attend selected educational conferences may be provided as long as the selection of students, residents or fellows who will receive the funds is made either by the academic or training institution or by the accredited sponsor with the full concurrence of the academic or training institution.

Conclusion: There is no question that commercial support can contribute significantly to the quality of CME activities. However, there have been abuses in the past and the ACCME new standards will help to assure scientific integrity of all $\mathrm{CME}$ activities that receive certification for credit.

The standards have evolved and I would suggest anyone that publishes and or lectures at CME activities should know the Standards because most lectures that I have observed do not comply with the requirements.

In my opinion, although medical journals have lagged behind ACCME standards with regards to conflict of interest, they have established their own policies on the matter. Almost all medical journals now require authors to disclose COI, however the same standards have not been employed for editors and reviewers. [4]

Haque et al, looked at 703 editors and COI policies at 60 medical journals. $57 \%$ of the journals had policies in place governing COI for editors, but only $21 \%$ publicly reported the disclosures. [4]

Journals and CME activities have focused on financial conflict of interest (FCOI) but is that sufficient? Certainly there can be other factors that can influence the behavior and actions of persons in a position of authority. A 2004 study, argued that “...the automatic nature of self-interest gives it a primal power to influence judgment and makes it difficult for people to understand its influence on their judgment, let alone eradicate its influence." [ [5]

There have been published examples of overtly biased actions by editors. "For example, an orthopedic surgeon, during his tenure as an editor published many studies in his journal favoring products from a company, which paid him millions of dollars in patent royalties." [ㅁ]

What about the potential issues of editors and or reviewers trying to gain favor by approving manuscripts submitted by key surgeons who influence appointments to key memberships in professional societies and committees. I suggest that we have to understand better what motivates behavior and what is the level of trust in a given profes- 
sional standard of behavior.

In 2007 The American Academy of Orthopaedic Surgeons (AAOS) adopted Standards of Professionalism on Orthopaedic-Industry Conflicts of Interest that require orthopaedic surgeon members to identify and disclose potential conflicts of interest to their patients. [7]

JISRF created a web page that deals with Patient-Physician Guide, Patient Disclosure Letter, Patient Disclosure Poster, and AAOS Patient-Physician Communications. This page is not intended to be and end all result on the subject but a convenient resource page. We recommend that you also check with your individual professional societies for their policies on disclosure. []]

\section{All Policy and Procedures can be Viewed on Reconstructive Review Website. [9]}

The following highlights some of our policies that pertain to COI.

The process of peer review assures the quality of the content in the articles, with the goal being new knowledge and skills that are of practical benefit to the readers of Reconstructive Review. The Editor-in-Chief and Managing Editor initially review all submissions. At this point articles may be rejected without peer review if it is felt that they are not of high enough quality or not relevant to Reconstructive Review. Once submissions pass initial review they are sent out for peer review.

To provide open-access, peer reviewed articles Reconstructive Review relies on individuals who are willing to take on the responsibility, and privilege, to review articles written by their peers. Please take a moment to look at the general guidelines we provide to reviewers that outline their purpose, good practices, and responsibilities.

\section{Double-blind Review Process and Timeframe}

Reconstructive Review operates a double-blind peerreview system; that is, reviewers and authors are not informed of each other's identities during the review process. If the reviewer, Managing Editor, and/or Editor-in-Chief feel more revisions are deemed necessary a submission may undergo several reviews.

- Reviewers must take care not to identify themselves, their patients, or their institutions within the body of their comments.

- Reviews are read by the assigned Managing Editor, who makes the preliminary decision to accept or decline, or to ask the author to revise the article. The Managing Editor may also request that the reviewer comment on an extensively revised article that he or she had reviewed previously in an earlier version.

- Reviews are to be returned in a timely manner, within
2 weeks of invitation, as determined by the Editorial Board of Directors. Because the Managing Editor's decision must wait until all reviews are complete, a delay by a single reviewer slows the editorial process. Reviewers agree to review an article only if they have the proper expertise and are confident that they can meet the deadline.

Based on the feedback from these reviewers and the judgment of the editorial team, a decision is given on the article. Possible decisions are to Accept Submission, Revisions Required, Resubmit for Review, and Decline Submission.

Once an article has been published in Reconstructive Review any ongoing, or post-publication review and/or commentaries are handled by submitting Letters to the Editor.

\section{Appeals}

If you believe the editorial team has incorrectly rejected your article, authors may send an appeal to the editorial office. To submit an appeal please send an email to the editorial office giving as much detail as possible about why you believe that your article has been incorrectly rejected. Please do not re-submit your article.

\section{Open Access Policy}

This journal provides immediate open access to its content on the principle that making research freely available to the public supports a greater global exchange of knowledge.

\section{Archiving}

This journal utilizes the PKP Private LOCKSS network and Portico to create a distributed archiving system among participating libraries and permits those libraries to create permanent archives of the journal for purposes of preservation and restoration. For more information please visit PKP Private LOCKSS network and Portico.

All content published on Reconstructive Review is digitally archived off site as well. When issues are created copies of full text articles are deposited on CrossRef. In addition, full backups are regularly performed by the site's hosting company and by Journal Editorial Services.

\section{Self-archiving}

Under the terms of the license, authors are entitled to deposit the final published version of their article in institutional and/or centrally organized repositories immediately upon publication, provided that Reconstructive Review is attributed as the original place of publication and that correct citation details are given. Authors are also strongly en- 
couraged to deposit the URL of their published article, in addition to the PDF version.

\section{Publication Ethics}

Authors should observe high standards with respect to publication ethics as set out by the Commission on Publication Ethics (COPE) and International Committee of Medical Journal Editors (ICMJE). Falsification or fabrication of data, plagiarism, including duplicate publication of the authors' own work without proper citation, and misappropriation of the work are all unacceptable practices. Any cases of ethical misconduct are treated very seriously and will be dealt with in accordance with the COPE guidelines. Reconstructive Review is currently registered with CrossRef and will be using their CrossCheck services to screen for plagiarism.

\section{Authorship}

All authors listed on the article should have contributed significantly to the experimental design, its implementation, or analysis and interpretation of the data. All authors should have been involved in the writing of the article at draft and any revision stages and should have read and approved the final version. Anyone who made major contributions to the writing of the article should be listed as an author (e.g. "ghost writing" is prohibited by Reconstructive Review). Any other individuals who made less substantive contributions to the experiment or the writing of the article should be listed in the acknowledgement section. Any change in authorship (including author order) after the initial article submission must be approved in writing by all authors.

\section{Originality}

By submitting your article to Reconstructive Review it is understood that this it is an original article and is unpublished work and is not under consideration elsewhere. Plagiarism, including duplicate publication of the author's own work, in whole or in part without proper citation is not tolerated by Reconstructive Review. Articles submitted to Reconstructive Review will be checked for originality using CrossCheck.

\section{Informed Consent}

Patients have a right to privacy that should not be infringed without informed consent. Articles should include a statement that the patient's written consent was obtained and any information, including illustrations, should be as anonymized as far as possible. Authors should indicate that local ethical committees have approved the design of the work or that it conforms to standards currently applied in the country of origin. The name of the authorizing body should be stated in the paper.

Patients' identities must be removed in all figures (i.e., X-rays, MRIs, charts, photographs, etc.). Written informed consent is required from any potentially identifiable patient or legal representative, and should be presented in either the Methods section or the Acknowledgements.

\section{Material Disclaimer}

The opinions expressed in Reconstructive Review are those of the authors and contributors, and do not necessarily reflect those of the editors, the editorial board, JISRF, or the organization to which the authors are affiliated.

\section{Conflict-of-Interest, Disclosures}

As part of the online submission process, corresponding authors are required to confirm whether they or their co-authors have any conflicts of interest to declare, and to provide details of these. If the Corresponding author is unable to confirm this information on behalf of all co-authors, the authors in question will then be required to submit a completed form to the Editorial Office. It is the Corresponding author's responsibility to ensure that all authors adhere to this policy.

\section{Charges}

All content published in Reconstructive Review is made freely available online to all under an Open Access model. Currently there are no charges associated with submitting an article to Reconstructive Review for peer-review and publication. There are no subscription fees and all content is available as full text in either PDF and/or HTML.

\section{Complaints}

This procedure applies to complaints about content of Reconstructive Review as well as the policies, procedures, or actions of Reconstructive Review's editorial staff. We welcome complaints as they provide an opportunity and a spur for improvement, and we aim to respond quickly, courteously, and constructively.

Our definition of a complaint is as follows:

- The complainant defines his or her expression of unhappiness as a complaint.

- We infer that the complainant is not simply disagreeing with a decision we have made or something we have published but think that there has been a failure of process - for example, a long delay or a rude response - or a severe misjudgment.

- The complaint must be about something that is within the responsibility of Reconstructive Review's content or process. 
Reconstructive Review is aware of the complaints stated below:

1. Authorship complaints

2. Plagiarism complaints

3. Multiple, duplicate, concurrent publication/Simultaneous submission

4. Research results misappropriation

5. Allegations of research errors and fraud

6. Research standards violations

7. Undisclosed conflicts of interest

8. Reviewer bias or competitive harmful acts by reviewers

\section{Policy for Handling Complaints}

If the Journal receives a complaint that any contribution to the Journal infringes intellectual property rights or contains material inaccuracies, libelous materials or otherwise unlawful materials, the Journal will investigate the complaint. Investigation may include a request that the parties involved substantiate their claims. The Journal will make a good faith determination whether to remove the allegedly wrongful material. A decision not to remove material should represent the Journal's belief that the complaint is without sufficient foundation, or if well-founded, that a legal defense or exemption may apply, such as truthfulness of a statement in the case of libel. Journal should document its investigation and decision. We strive to ensure that Reconstructive Review is of the highest quality and is free from errors. However, we accept that occasionally mistakes might happen.

\section{Editorial Complaints Policy}

The Managing Editor and staff of Reconstructive Review will make every endeavor to put matters right as soon as possible in the most appropriate way, offering right of reply where necessary. As far as possible, we will investigate complaints in a blame-free manner, looking to see how systems can be improved to prevent mistakes occurring.

\section{Guiding Principles}

Our general approach to complaints is that they are a rare but inevitable part of a process that involves putting together complex material at great speed. We accept that we make mistakes and try to treat all complaints with urgency, however small. We believe that timely solutions can prevent problems escalating. All substantial errors and complaints are referred to senior executives within the editorial staff as a matter of course.

The procedure outlined below aims to be fair to those making complaints and those complained about. All com- plaints will be acknowledged (within three working days if by email). If possible a definitive response will be made within two weeks. If this is not possible an interim response will be given within two weeks. Interim responses will be provided until the complaint is finally resolved. If the complainant remains unhappy, complaints should be escalated to the editor, whose decision is final.

\section{How to Make a Complaint}

Complaints about editorial content should be made as soon as possible after publication, preferably in writing by email to: editors@ReconstructiveReview.org.Please write your complaint with journal title, vol. no., issue no., paper title, and page no.

\section{Corrections, Retractions, and Expressions of Concern}

JISRF, Reconstructive Review and its editors take all reasonable steps to identify and prevent the publication of papers where research misconduct has occurred, including plagiarism (all submissions screened using Ithenticate $\AA$ ), citation manipulation, and data falsification/fabrication, among others. In no case does Reconstructive Review or its editors encourage such misconduct, or knowingly allow such misconduct to take place. In the event that Reconstructive Review's publisher or editors are made aware of any allegation of research misconduct relating to a published article in the journal, JISRF and the senior editorial staff shall follow COPE's guidelines in dealing with allegations. In addition, Reconstructive Review utilizes a service provided by Crossref called Crossmark. This service gives readers quick and easy access to the current status of a piece of content. With one click, you can see if content has been updated, corrected or retracted.

The issue of conflict of interest and what and how to disclose will be an ongoing area of concern and debate for years to come.

The following quote from Phyllis Pettit Nassi clearly states the challenge. "When you talk about trust you have to know the way a group thinks, how they interact, how they communicate, how they educate. You have to know what their roles and relationships are. What are their values? Their practices? What are the expected behaviors?"

Members of JISRF and Reconstructive Review will stay diligent with regard to $\mathrm{COI}$ and disclosure issues and from time to time will update our policies and procedures. We welcome comments on this subject and look forward to addressing concerns within a common sense approach. 


\section{References}

1. McTighe T, Vise G.T., Bechtol C.O., CME Conflict of Interest, AAOS Scientific Exhibit 1993 San Francisco, CA.

2. Boulding M, The Statutory Basis for FDA Regulation of Scientific and Educational Information. Journal of Pharmacy and Law, Vol. 4, No. 2, pages 123-142 (1995)

3. Standards for Commercial Support: Standards to Ensure the Independence of CME Activities $^{\text {SM }}$ https://www.accme.org/sites/default/files/2019-01/174 20190118 ACCME Standards for Commercial Support.pdf

4. Haque W, Minhajuddin A, Gupta A, Agrawal D, Conflicts of interest of editors of medical journals. Published: May 18, 2018. doi: 10.1371/journal.pone.0197141

5. Moore DA L. Self-Interest, Automaticity, and the Psychology of Conflict of Interest. Social Justice Research. 2004;17:189.

6. Journal-Sentinel M. Journal editor gets royalties as articles favor devices Dec 2009 [07/28/16]. Available from: http://www.jsonline.com/watchdog/watchdogreports/80036277.html.

7. Patient Discussion Guide AAOS. http://www.jisrf.org/pdfs/patient-discussionguide.pdf

8. http://www.jisrf.org/professional-disclosure-jisrf.html

9. https://reconstructivereview.org/ojs/index.php/rr/about/ $\underline{\text { editorialPolicies\#custom-7 }}$

\begin{abstract}
SUBMISSION HISTORY
Submitted: March 6, 2019

Reviewed: March 10, 2019

Accepted: March 11, 2019

Published: March 31, 2019

AUTHOR AFFILIATIONS

1 Timothy McTighe, Dr HS (hc); Joint Implant Surgery \& Research Foundation, 46 Chagrin Shopping Plaza, \#117, Chagrin Falls, OH 44022 US

(Direct reprint requests to Timothy McTighe, tmct@jisrf.org)

\section{AUTHOR DISCLOSURES}

The authors declare that there are no disclosures regarding the publication of this paper.

\section{COPYRIGHT \& OPEN ACCESS}

(C) 2019 McTighe. All rights reserved.

Authors retain copyright and grant the journal right of first publication with the work. Reconstructive Review is an open access publication and follows the Creative Commons Attribution-NonCommercial CC BY-NC. This

license allows anyone to download works, build upon the material, with others for non-commercial purposes as long as they credit the senior author, Reconstructive Review, and the Joint Implant Surgery \& Research Foundation (JISRF). An example credit would be: "Courtesy of (senior author's name), Reconstructive Review, JISRF, Chagrin Falls, Ohio".
\end{abstract}

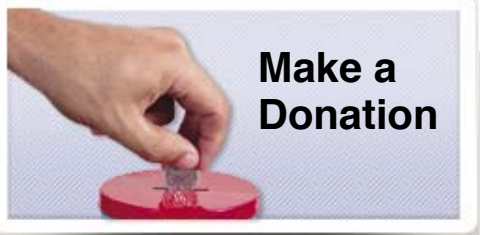

\section{Play a Role in Our Ground Breaking Research}

erhaps you were a patient and you were able to regain an important part of your life. Or, perhaps you are simply someone interested in medical research and seeking a new way to participate. Whatever the case, your

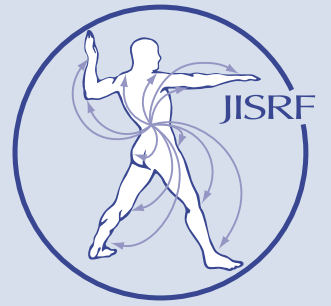
generosity in helping to fund research is critical to our success - and much appreciated.

The Joint Implant Surgery \& Research Foundation is a not-for-profit 501(c)(3) corporation. Your contributions enable scientific discoveries that will help future patients. Contributions over the years from people like you have helped to shape orthopaedics today.

\section{Contributions}

Donations of any amount will immediately be put to use to fund ongoing and future orthopaedic research projects.

\section{How to Give}

- Your gift of cash, securities or other negotiable assets is immediately put to use in our research.

- Your contributions are fully tax deductible as specified under Section 501(c)(3) regulations.

For more information please visit our website at www.jisrf.org or contact us at:

Joint Implant Surgery \& Research Foundation 46 Chagrin Shopping Plaza, \#117 Chagrin Falls, OH 44022 440.785.9154 